\title{
Rancang Ulang Tata Letak Fasilitas Produksi untuk Efisiensi Produksi Kopi di PT Sinar Mayang Lestari Menggunakan Metode Systematic Layout Planning dan Software Blocplan
}

\author{
Muhammad Milzam Abdurrahmad ${ }^{1}$, Roni Kastaman ${ }^{2 *}$ dan Totok Pujianto² \\ ${ }^{1}$ Program Studi Teknologi Industri Pertanian, Fakultas Teknologi Industri Pertanian, \\ Universitas Padjadjaran \\ ${ }^{2}$ Fakultas Teknologi Industri Pertanian, Universitas Padjadjaran \\ J1. Raya Bandung-Sumedang KM 21 Jatinangor, Jawa Barat 45363 \\ *Alamat korespondensi: roni.kastaman@unpad.ac.id
}

\begin{tabular}{lrc}
\hline \multicolumn{2}{c}{ INFO ARTIKEL } & ABSTRACT/ABSTRAK \\
\hline Diterima: & 03-06-2021 & \\
Direvisi: & 04-07-2021 & Manufacturing Facility Layout Planning for Coffee Production Efficiency in PT \\
Dipublikasi: 11-08-2021 & Sinar Mayang Lestari Using Systematic Layout Planning (SLP) Method and \\
& & Blocplan Software
\end{tabular}

Keywords:

Blocplan,

Manufacturing

facility layout

planning, Material

handling costs, SLP

Kata Kunci:

Blocplan,

Perancangan tata letak fasilitas produksi, Ongkos material handling, SLP
Indonesia is still unable to meet the national and international demand for coffee. Indonesia's total coffee production in 2017 was 717,961 tons, which was lower than Indonesia's coffee needs for the national and international markets which reached 747,790 tons. This study aimed to improve the existing layout at PT Sinar Mayang Lestari in order to increase the quantity and quality of PT Sinar Mayang Lestari's coffee production in order to create optimal production and try to help meet the needs of Indonesian coffee. PT Sinar Mayang Lestari is a coffee growing and processing company located in Pangalengan, Bandung Regency. The re-planning of the layout of PT Sinar Mayang Lestari's production facilities was carried out using the Systematic Layout Planning (SLP) method and Blocplan software. It produced 20 layout alternatives that could be selected to decide which alternative was the most efficient based on the least material handling cost. The result of this study showed that the layout alternative using SLP with minimalizing distance between departments was about $33.65 \%$ and material handling cost reduction was about $62.94 \%$ from the actual layout. Facility layout re-planning of the production system in PT Sinar Mayang Lestari was considered more effective using the SLP method rather than Blocplan because the SLP method took into account more supporting factors than the Blocplan method.

Indonesia masih belum bisa memenuhi permintaan kopi nasional maupun internasional. Total produksi kopi Indonesia pada tahun 2017 sebesar 717.961 ton yang lebih rendah dari kebutuhan kopi Indonesia untuk pasar nasional dan internasional yang mencapai 747.790 ton. Penelitian ini berujuan untuk memperbaiki layout yang ada di PT Sinar Mayang Lestari agar dapat meningkatkan kuantitas dan kualitas produksi kopi PT Sinar Mayang Lestari demi menciptakan produksi yang optimal dan berupaya membantu memenuhi kebutuhan kopi Indonesia. PT Sinar Mayang Lestari merupakan perusahaan penanaman dan pengolahan kopi yang berlokasi di Pangalengan, Kabupaten Bandung. Perancangan ulang tata letak fasilitas produksi PT Sinar Mayang Lestari dilakukan dengan metode Systematic Layout Planning (SLP) dan software Blocplan. Dihasilkan 20 layout 
alternatif yang dapat dibuat yang kemudian diseleksi untuk menentukan satu layout alternatif yang paling efisien berdasarkan ongkos material handling terkecil. Hasil penelitian menunjukkan layout alternatif hasil metode SLP dengan minimalisasi jarak antar departemen sekitar 33,65\% dan pengurangan ongkos material handling sekitar $62,94 \%$ dari layout aktual. Perancangan ulang tata letak fasilitas produksi PT. Sinar Mayang Lestari dinilai lebih efektif menggunakan metode SLP dibanding Blocplan karena metode SLP memperhitungkan lebih banyak faktor pendukung daripada metode Blocplan.

\section{PENDAHULUAN}

Potensi pengembangan industri kopi di Indonesia sangat besar, terlihat dari permintaan kopi yang terus meningkat dari tahun ke tahun (Direktorat Jenderal Perkebunan, 2019). Hasil penelitian International Coffee Organization (2018) menunjukkan adanya peningkatan permintaan kopi dari tahun 2015 hingga 2019 yaitu meningkat sebesar 5,49\% dari 273.000 ton menjadi 288.000 ton.

Dilihat dari data produksi kopi yang ada, Indonesia masih belum bisa memenuhi permintaan kopi nasional dan internasional. Berdasarkan data Direktorat Jenderal Perkebunan (2019), pada tahun 2017 Indonesia mengekspor kopi sebanyak 467.790 ton. Total produksi kopi Indonesia pada tahun 2017 sebesar 717.961 ton, dari jumlah tersebut bisa disimpulkan bahwa sisa kopi yang dapat dijual di dalam negeri yaitu sebesar 250.171 ton padahal konsumsi kopi Indonesia pada tahun 2017 sebesar 280.000 ton (International Coffee Organization, 2018). Oleh karena itu Indonesia masih harus berupaya meningkatkan produktivitas tanpa perlu mengurangi jumlah ekspor yang ada untuk memenuhi kebutuhan pasar nasional maupun internasional. Dalam upaya pemenuhan permintaan konsumen, terdapat berbagai faktor yang perlu diperhatikan, salah satunya adalah faktor produksi. Proses produksi yang baik akan menghasilkan produk yang bersih, bebas dari kontaminasi bahan kimia, memiliki mutu fisik maupun biologi yang baik dari. Proses produksi yang baik dapat meminimalisasi kebutuhan biaya dan secara tidak langsung dapat mengalokasikan biaya untuk pengembangan produksi menjadi lebih besar. Salah satu faktor yang perlu diperhatikan dalam proses produksi adalah tata letak fasilitas produksi. Tata letak fasilitas pada proses produksi juga menjadi salah satu faktor yang menentukan kualitas produk itu sendiri. Menurut Wignjosoebroto (2009), tata letak pabrik atau tata letak fasilitas merupakan tata cara pengaturan fasilitas pabrik yang memiliki tujuan untuk menciptakan proses produksi yang lebih optimal.

PT Sinar Mayang Lestari adalah perusahaan penanaman kopi yang berlokasi di Desa Pasir Mulya, Kecamatan Pangalengan, Kabupaten Bandung, Jawa Barat, Indonesia. Luas tanah yang dimiliki PT Sinar Mayang Lestari kurang lebih 70 hektar. Berdasarkan observasi awal di lokasi produksi PT Sinar Mayang Lestari, tata letak produksi PT Sinar Mayang Lestari masih perlu pembenahan karena dinilai kurang efisien pada jalur perpindahan material saat terjadi bolak-balik jalur produksi, sehingga memperpanjang jalur perpindahan bahan dan meningkatkan biaya produksi. Systematic layout planning (SLP) dan Blocplan merupakan metode perancangan ulang tata letak fasilitas produksi. Metode SLP merupakan metode desain tata letak berdasarkan jarak perpindahan material minimum. Hasil penelitian Pangestika dkk. (2016) menunjukkan bahwa panjang jalur perpindahan material selama produksi produk farmasi dan kosmetik bagian OT cair pada PT IKP berhasil dikurangi sebesar 229,5 $\mathrm{m}$ dengan menggunakan metode SLP. Sementara itu, software Blocplan merupakan program untuk membantu perancangan otomatis yang memerlukan masukan dari beberapa data yang dibutuhkan (Choir dkk., 2017). Pada penelitian Choir dkk. (2017), Blocplan digunakan untuk mengukur permintaan ukuran fasilitas yang efektif. Hasil penelitian Siregar dkk. (2013) menunjukkan bahwa metode Blocplan secara efektif menurunkan momen perpindahan sebesar 1.482.180 m/tahun. Pertimbangan terakhir dalam perancangan ulang tata letak fasilitas produksi ini adalah jarak pemindahan material dan biaya material handling. Tujuan penelitian ini adalah memperbaiki layout yang ada di PT Sinar Mayang Lestari agar dapat meningkatkan kuantitas dan kualitas produksi kopi PT Sinar Mayang Lestari. Hasil yang diharapkan adalah mengurangi jarak perpindahan dan meminimalkan biaya produksi 
sehingga biaya produksi dapat digunakan untuk peningkatan volume produksi demi meningkatkan kebutuhan kopi di Indonesia.

\section{BAHAN DAN METODE}

Penelitian dilakukan pada PT Sinar Mayang Lestari yang terletak di wilayah Pangalengan
Kabupaten Bandung. Penelitian dilaksanakan pada bulan Juli hingga Agustus 2020. Jenis penelitian yang digunakan adalah penelitian tindakan (action research). Model action research merupakan model penelitian yang berpraktek dan berteori, atau menggabungkan teori sekaligus melaksanakan dalam praktek (Hasan, 2009). Tahapan penelitian dapat dilihat secara lebih rinci pada Gambar 1.

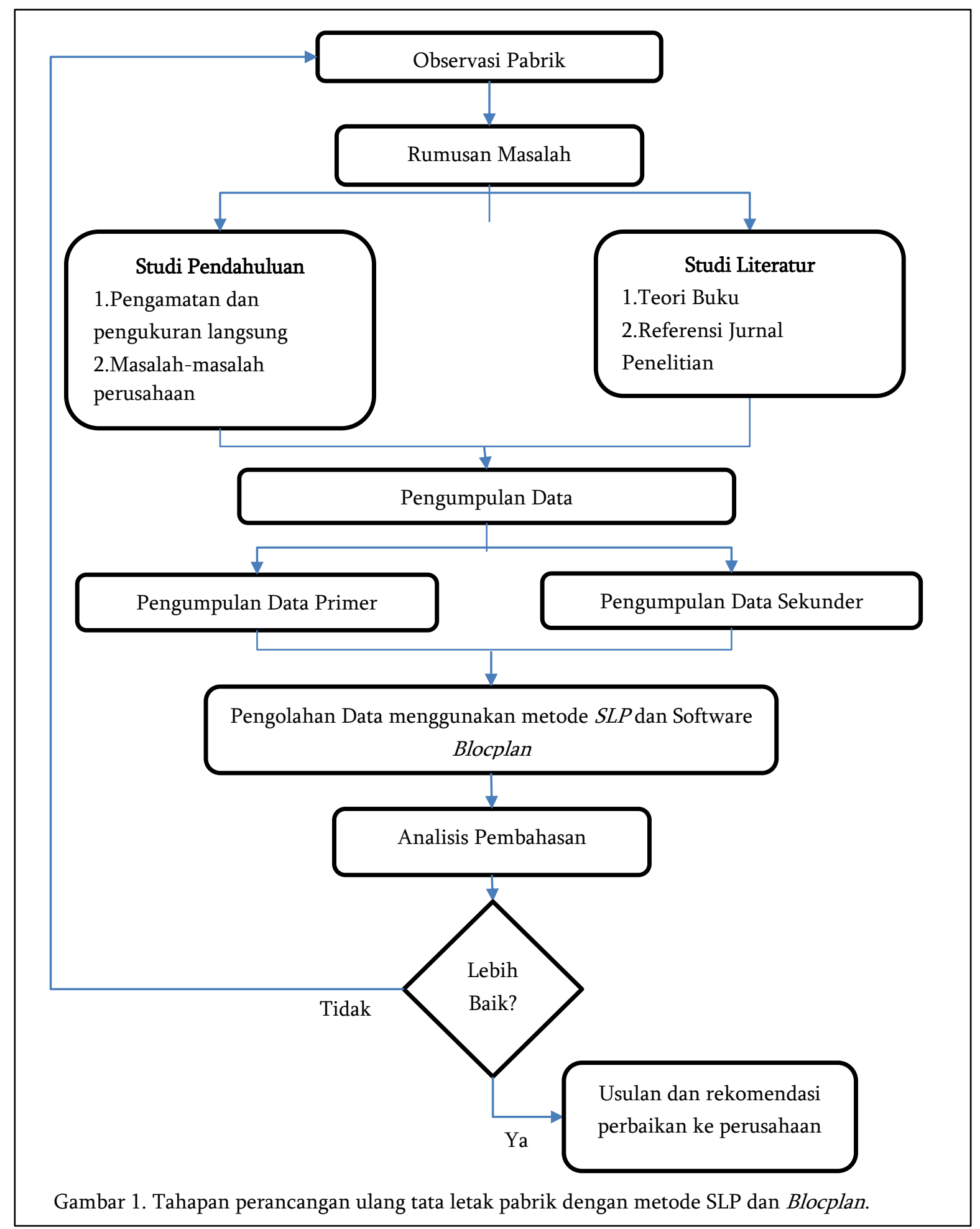


Pengambilan data dilakukan secara langsung dengan mendatangi lokasi penelitian dan melakukan kegiatan pengumpulan data yang terdiri atas dua kegiatan yaitu pengamatan langsung terhadap obyek (observasi) dan wawancara. Pada tahapan observasi dilakukan pengenalan dengan perusahaan, mengamati aktivitas-aktivitas yang dilakukan perusahaan khususnya pada proses produksi kopi, juga melakukan observasi pada proses pengolahan kopi. Sementara itu, wawancara dilakukan untuk mendapatkan informasi seperti sejarah perusahaan, stuktur perusahaan dan profil perusahaan lainnya.

Data hasil observasi dan wawancara kemudian diolah dengan metode sebagai berikut:

1. Pengolahan data dengan metode Systematic Layout Planning (SLP)

Pengolahan data menggunakan metode SLP memiliki langkah-langkah sebagai berikut (Wignjosoebroto, 2009):

1. Menggambar Activity Relationship Chart

2. Menggambar Activity Relationship Diagram

3. Mempertimbangkan modifikasi data dan batasan praktis

4. Merancang alternatif tata letak

5. Menghitung jarak tempuh dan ongkos material handling

2. Pengolahan data menggunakan software Blocplan

Langkah-langkah dalam pengolahan data sebagai berikut (Nursandi dkk., 2014):

1. Memasukkan data jumlah departemen

2. Memasukkan data nama dan luas setiap departemen
3. Memasukkan data activity relationship diagram

4. Memasukkan data score dari activity relationship diagram

5. Memilih alternatif dengan jumlah r-score yang paling kecil

6. Merancang usulan dari software blocplan

7. Menghitung jarak tempuh dan ongkos material handling

\section{HASIL DAN PEMBAHASAN}

Lahan pengolahan kopi PT Sinar Mayang Lestari memiliki luas sekitar 1022,25 m² yang terdiri atas 16 departemen. Departemen tersebut terdiri atas 8 departemen yang berkaitan langsung dengan pengolahan, dan 8 departemen lainnya sebagai sarana dan pra-sarana non-pengolahan. Layout aktual dari luas fasilitas pengolahan kopi di PT Sinar Mayang Lestari dapat dilihat pada Gambar 2.

PT Sinar Mayang Lestari memiliki 3 proses produksi kopi yaitu natural, fullwash, dan honey. Jarak tempuh dan ongkos material handling dari alur proses produksi layout aktual dapat dilihat pada Tabel 1. Pada Tabel 1 dapat dilihat bahwa jumlah ongkos material handling untuk satu hari adalah sebesar Rp 203.645. Angka tersebut kemungkinan dikarenakan faktor jarak antar departemen yang terlalu jauh karena banyaknya ruang kosong dan alur proses produksi yang kurang efisisen. Total jarak antar departemen terkait adalah $416 \mathrm{~m}$, sehingga jarak tempuh material handling adalah sebesar $1.266 \mathrm{~m}$. 


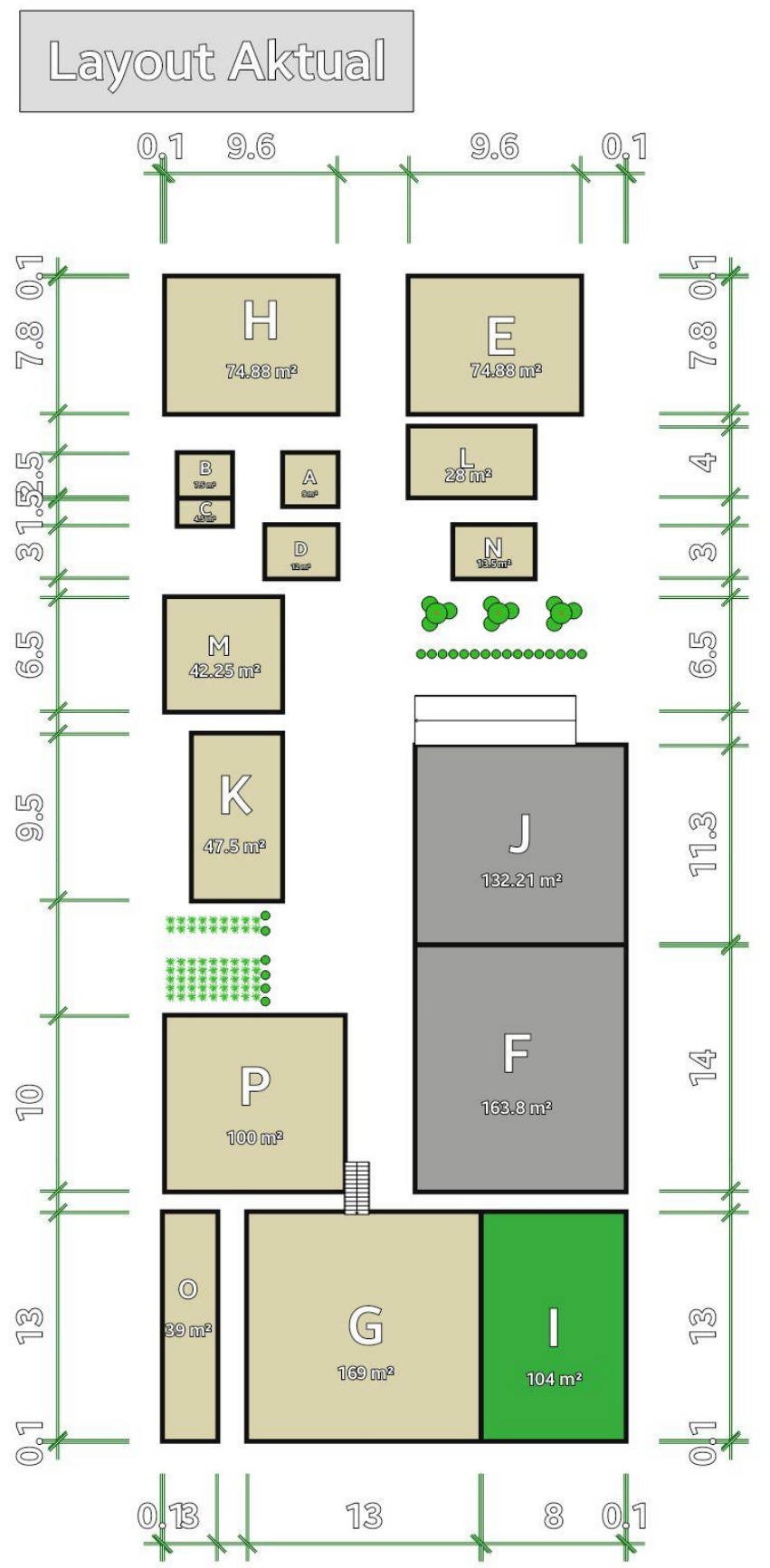

Gambar 2. Layout aktual fasilitas pengolahan kopi di PT. Sinar Mayang Lestari sebelum modifikasi.

Tabel 1. Jarak tempuh dan ongkos material handling $(\mathrm{OMH})$ produksi kopi aktual PT Sinar Mayang Lestari

\begin{tabular}{cllll}
\hline No. & $\begin{array}{c}\text { Nama } \\
\text { proses }\end{array}$ & $\begin{array}{c}\text { Jarak } \\
(\mathrm{m})\end{array}$ & $\begin{array}{c}\text { Total } \\
\text { jarak }(\mathrm{m})\end{array}$ & $\begin{array}{c}\text { OMH } \\
\text { total }(\mathrm{Rp})\end{array}$ \\
\hline 1. & Natural & 155,5 & 484 & 97.867 \\
\hline 2. & Fullwash & 115,5 & 276,5 & 42.332 \\
\hline 3. & Honey & 145 & 505,5 & 63.447 \\
\hline \multicolumn{2}{l}{ Total } & 416 & 1.266 & 203.645 \\
\hline
\end{tabular}

Sebelum melakukan perancangan ulang tata letak, hal yang perlu dilakukan adalah membuat Activity Relationship Chart (ARC) untuk mengetahui keterkaitan dan hubungan antar departemen. Activity Relationship Chart PT Sinar Mayang Lestari dapat dilihat pada Gambar 3. 


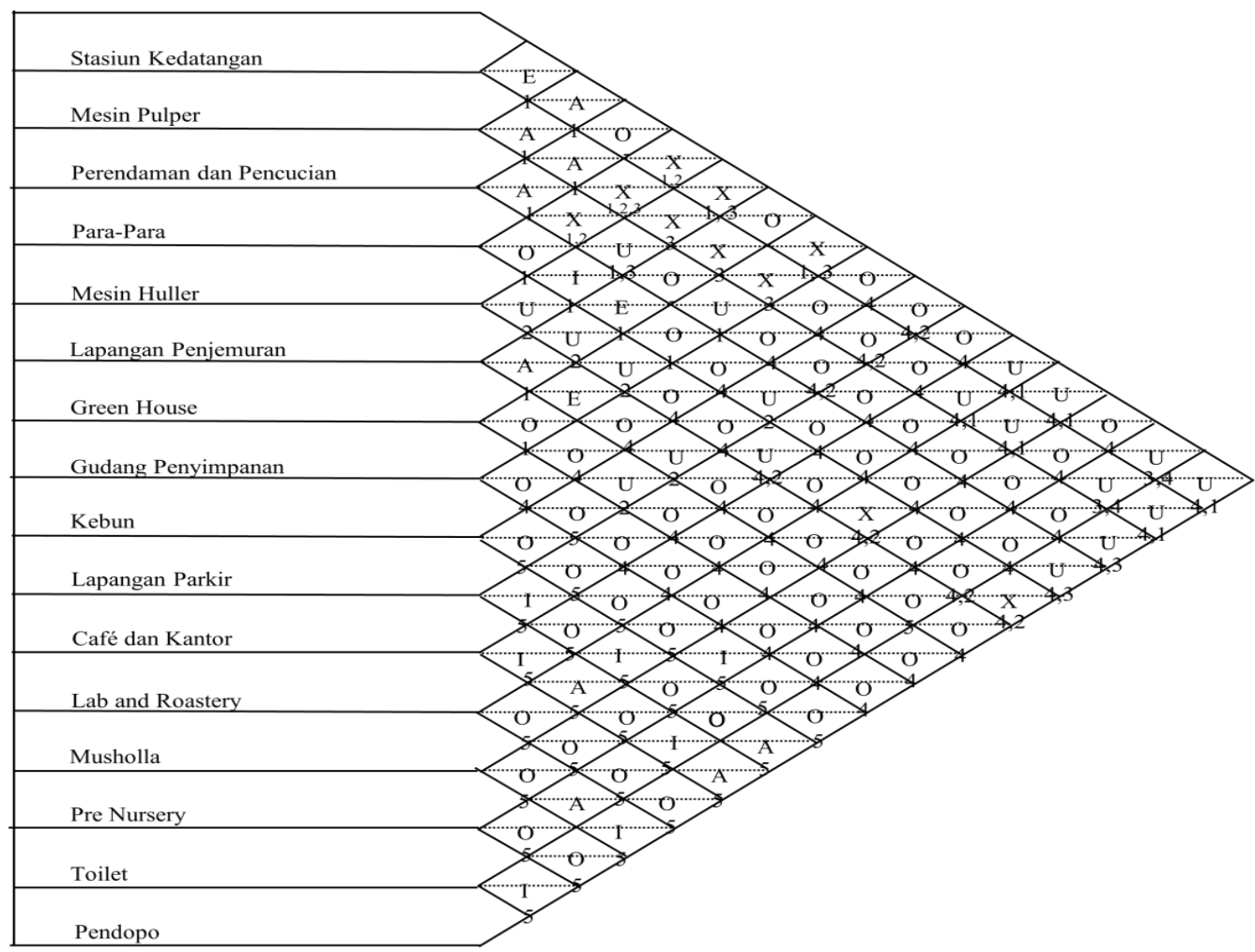

Gambar 3. Activity Relationship Chart (ARC) PT Sinar Mayang Lestari.

Pembuatan ARC didapatkan dari hasil wawancara langsung kepada pekerja di PT Sinar Mayang Lestari. Keterangan keterkaitannya adalah sebagai berikut: A semakin harus berdekatan, I sangat penting berdekatan, E penting berdekatan, $\mathrm{O}$ kedekatan biasa, $\mathrm{U}$ tidak diinginkan untuk berdekatan dan $\mathrm{X}$ tidak boleh berdekatan. Hubungan tersebut ditinjau dari 5 aspek yang terdiri dari urutan proses, efek debu dan kotoran, efek bau tidak sedap, keterkaitan dengan proses produksi dan keterkaitannya dengan fasilitas lain. Debu, kotoran, dan bau menjadi poin yang juga harus menjadi perhatian karena kopi mempunyai kemiripan dengan sifat karbon aktif sebagai adsorben yaitu bahan yang dapat menyerap aroma di sekitarnya dan dapat memengaruhi aroma kopi setelah di proses (Riyanta \& Febriyanti, 2018). Oleh karena itu, kotoran dan bau tak sedap lebih baik dijauhkan agar kualitas hasil pengolahan kopi maksimal.

\section{Perancangan Ulang Tata Letak Menggunakan Metode Systematic Layout Planning}

Tahap pertama yang perlu dilakukan untuk merancang tata letak ulang menggunakan metode SLP yaitu membuat ARD. ARD adalah suatu teknik yang digunakan untuk mendapatkan gambaran tentang tata letak ruangan terhadap ruangan lainnya. Gambaran ARD dapat dilihat pada Gambar 4. 


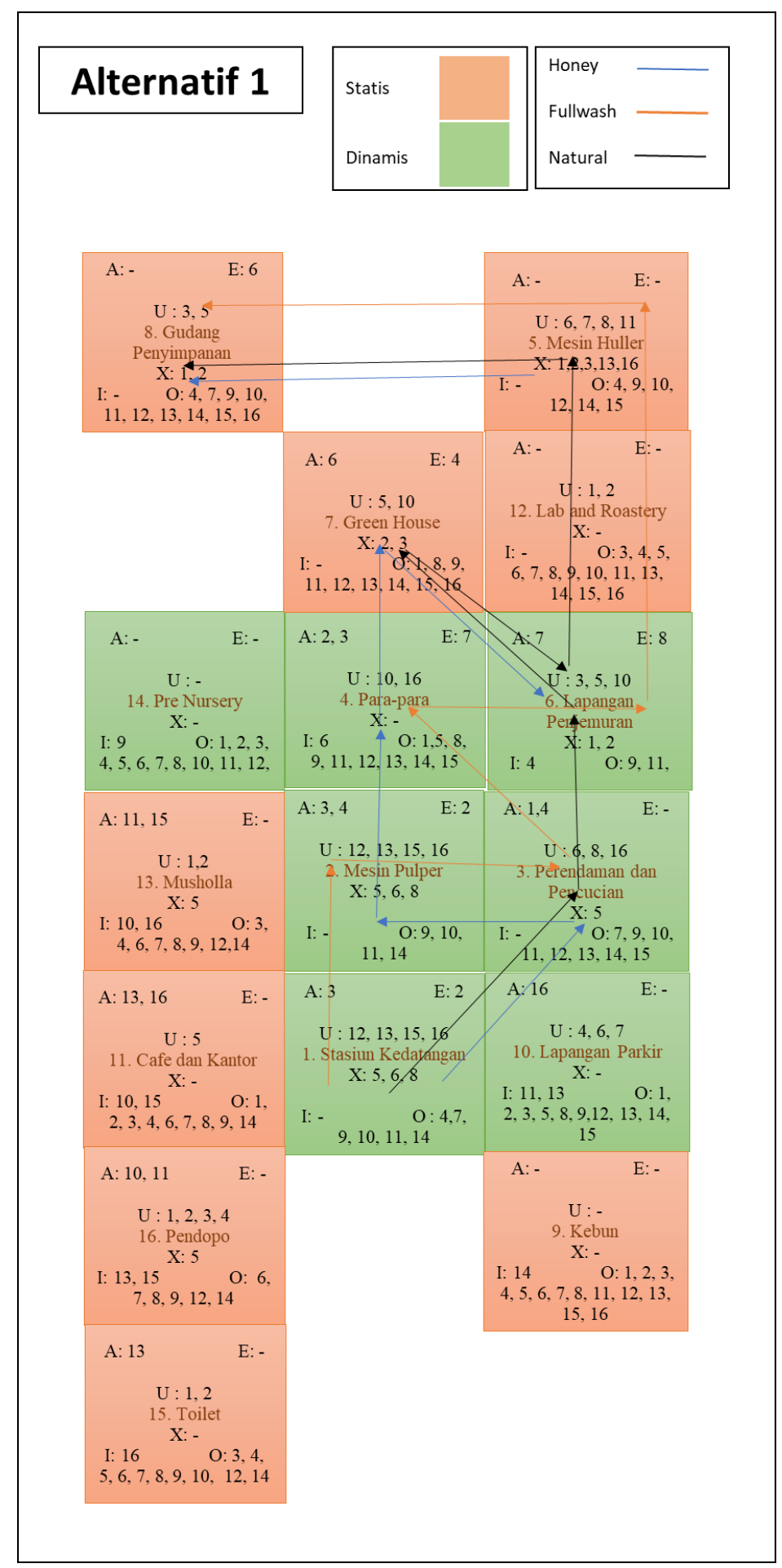

Gambar 4. ARD alternatif menggunakan SLP.

Pembuatan ARD akan mempermudah telah dibuat pada ARD. Layout alternatif usulan membuat layout usulan perbaikan. Layout denah perbaikan dengan metode SLP dapat dilihat pada alternatif letaknya didasari dari pola aliran yang Gambar 5. 


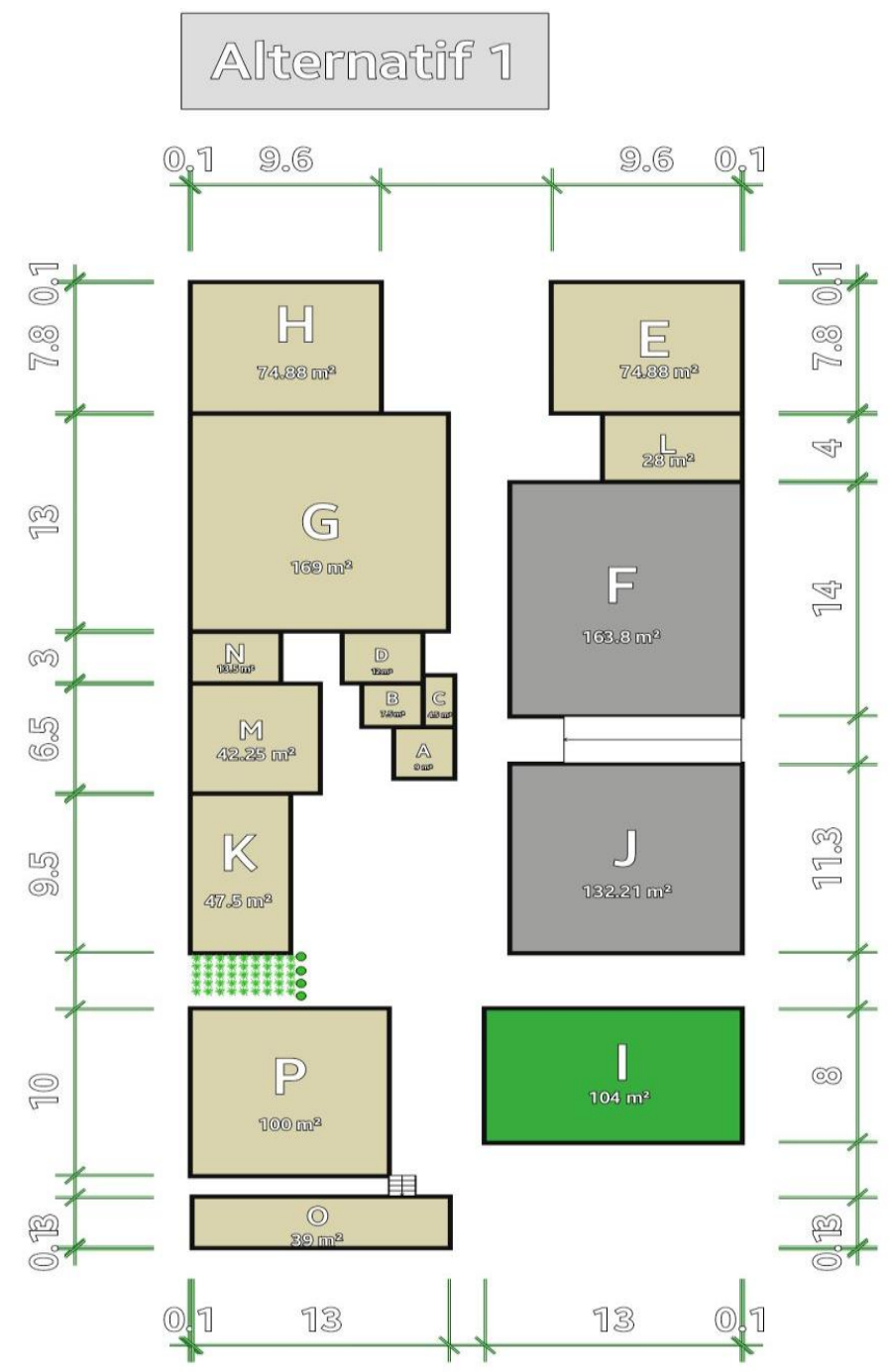

Gambar 5. Layout alternatif usulan perbaikan tata letak metode SLP.

Pada layout alternatif ini perlu dihitung juga jarak tempuh dan ongkos material departemen untuk setiap proses produksinya. Jarak tempuh dan ongkos material handling layout aktual dapat dilihat pada Tabel 2.

Tabel 2. Jarak tempuh dan ongkos material handling metode SLP

\begin{tabular}{cllll}
\hline No. & $\begin{array}{c}\text { Nama } \\
\text { proses }\end{array}$ & $\begin{array}{c}\text { Jarak } \\
(\mathrm{m})\end{array}$ & $\begin{array}{c}\text { Total } \\
\text { jarak }(\mathrm{m})\end{array}$ & $\begin{array}{c}\text { OMH } \\
\text { total }(\mathrm{Rp})\end{array}$ \\
\hline 1. & Natural & 103 & 576 & 49.935 \\
\hline 2. & Fullwash & 78 & 172,5 & 12.296 \\
\hline 3. & Honey & 95 & 160 & 13.226 \\
\hline Total & & 276 & 908,5 & 203.645 \\
\hline
\end{tabular}

Alternatif yang terpilih melalui studi ini berhasil memangkas jarak perpindahan dan ongkos material handling. Beberapa departemen produksi dapat direlokasi agar tidak membutuhkan banyak waktu dan tenaga dalam proses perpindahan bahan dari satu departemen ke departemen selanjutnya.

\section{Perancangan Ulang Tata Letak Menggunakan Metode Blocplan}

Penentuan tata letak fasilitas menggunakan algoritma blocplan ditentukan berdasarkan tiga score, yaitu $r$-score, adjacency score, dan rel-dist score. Nilai $r$-score adalah nilai efisiensi dari sebuah tata letak yang dihasilkan, adjacency score (adj score) adalah nilai kedekatan dari sebuah fasilitas berdasarkan ARC yang telah ditentukan, rectilinear distance score (rel-dist score) adalah jumlah keseluruhan jarak perpindahan material antar fasilitas (Husen dkk., 2020). Urutan pemilihan tata letak fasilitas usulan dipilih berdasarkan r-score terbesar, selanjutnya jika ada $r$-score yang sama dilanjutkan dengan pemilihan adjacency score terbesar, setelah dipilih berdasarkan nilai tertinggi 
jika masih ada adjacency score yang sama sedangkan dilanjutkan dengan memilih berdasarkan rel-dist score terendah (Husen dkk., 2020). Setelah pembentukan layout awal maka Algoritma Blocplan akan melakukan iterasi secara otomatis sebanyak 20 kali hingga menciptakan 20 alternatif layout. Hasil dari 20 iterasi tersebut dapat dilihat pada Tabel 3.

Tabel 3. Skor Blocplan

\begin{tabular}{|c|c|c|c|}
\hline Iterasi & Adj score & $r$-score & Rel-dist score \\
\hline 1. & $0,477^{*}(19)$ & $0,60 *(19)$ & $1201{ }^{*}(2)$ \\
\hline 2. & $0,52 *(12)$ & $0,78 *(3)$ & $-529 *(18)$ \\
\hline 3. & $0,51 *(13)$ & $0,67 *(12)$ & $543 *(8)$ \\
\hline 4. & $0,45 *(20)$ & $0,63 *(16)$ & $834 *$ *(6) \\
\hline 5. & $0,58 *(3)$ & $0,80 *(2)$ & $-818 *(19)$ \\
\hline 6. & $0,55 *(6)$ & $0,66 *(14)$ & $750 *$ * $(7)$ \\
\hline 7. & $0,60 *(1)$ & $0,71 *(6)$ & $164 *(15)$ \\
\hline 8. & $0,50 *(16)$ & $0,75 *(4)$ & $-121 *(17)$ \\
\hline 9. & $0,55 *(4)$ & $0,67^{*}(11)$ & 446 * (10) \\
\hline 10. & $0,55^{*}(6)$ & $0,66^{*}(13)$ & $410 *(11)$ \\
\hline 11. & $0,51 *(14)$ & $0,61 *(18)$ & $1082 *(3)$ \\
\hline 12. & $0,48 *(18)$ & $0,69 *(8)$ & $394 *(12)$ \\
\hline 13. & $0,51 *(14)$ & $0,60 *(20)$ & $1315^{*}(1)$ \\
\hline 14. & $0,55 *(6)$ & $0,68 *(9)$ & $382 *(13)$ \\
\hline 15. & $0,55 *(4)$ & $0.63^{*}(15)$ & $918 *(5)$ \\
\hline 16. & $0,55 *(6)$ & $0,74 *(5)$ & $-62 *(16)$ \\
\hline 17. & $0,53 *(11)$ & $0,68 *(10)$ & $452 *(9)$ \\
\hline 18. & $0,55^{*}(6)$ & $0,82 *(1)$ & $-921 *(20)$ \\
\hline 19. & $0,59 *(2)$ & $0,70 *(7)$ & 237 * (14) \\
\hline 20. & $0,49 *(17)$ & $0,62 *(17)$ & $973 *(4)$ \\
\hline
\end{tabular}

Keterangan: *urutan dari nilai terbesar ke terkecil

Angka-angka pada Tabel 3 adalah hasil perhitungan nilai kedekatan (adj score), nilai efisiensi ( $r$-score), dan nilai jumlah keseluruhan perpindahan material (real-dist score) yang dilakukan menggunakan software Blocplan terhadap layout aktual PT Sinar Mayang Lestari. Berdasarkan angka $r$-score yang terbesar, maka layout alternatif 18 dipilih menjadi layout usulan perbaikan menggunakan metode Blocplan. Hal tersebut dikarenakan semakin besar nilai $r$-score, maka nilai efisiensi layout alternatif akan semakin baik (Husen dkk., 2020). Dalam kasus ini, layout alternatif 18 menjadi layout alternatif dengan nilai efisiensi paling baik di antara alternatif lainnya. Layout 18 dapat dilihat pada Gambar 6.

Pada layout alternatif ini perlu dihitung juga jarak tempuh dan ongkos material departemen untuk setiap proses produksinya. Jarak tempuh dan ongkos material handling layout aktual dapat dilihat pada Tabel 4. Rancangan tata letak pabrik yang baru dengan metode Blocplan menghasilkan OMH yang lebih sedikit dibandingkan tata letak awal yaitu senilai Rp 185.097. Dengan jumlah produksi yang sama dengan yang ada pada tata letak aktual, panjang lintasan material handling pada rancangan tata letak pabrik dengan Blocplan adalah sepanjang $198 \mathrm{~m}$, sehingga total perpindahan bahan menjadi sepanjang $760 \mathrm{~m}$ per hari nya. Rancangan tata letak pabrik dengan Blocplan ini memiliki OMH yang besar karena membutuhkan alat bantu mobil bak dalam proses pemindahannya yang mempunyai jarak perpindahan yang cukup jauh.

Tabel 4. Jarak tempuh dan Ongkos Material Handling metode Blocplan

\begin{tabular}{ccccc}
\hline No. & $\begin{array}{c}\text { Nama } \\
\text { proses }\end{array}$ & $\begin{array}{c}\text { Jarak } \\
(\mathrm{m})\end{array}$ & $\begin{array}{c}\text { Total jarak } \\
(\mathrm{m})\end{array}$ & $\begin{array}{c}\text { OMH } \\
\text { total }(\mathrm{Rp})\end{array}$ \\
\hline 1. & Natural & 162,6 & 196,8 & 64.201 \\
\hline 2. & Fullwash & 125,4 & 211,8 & 92.715 \\
\hline 3. & Honey & 198 & 351,6 & 28.182 \\
\hline & Total & 486 & 760,2 & 185,097 \\
\hline
\end{tabular}



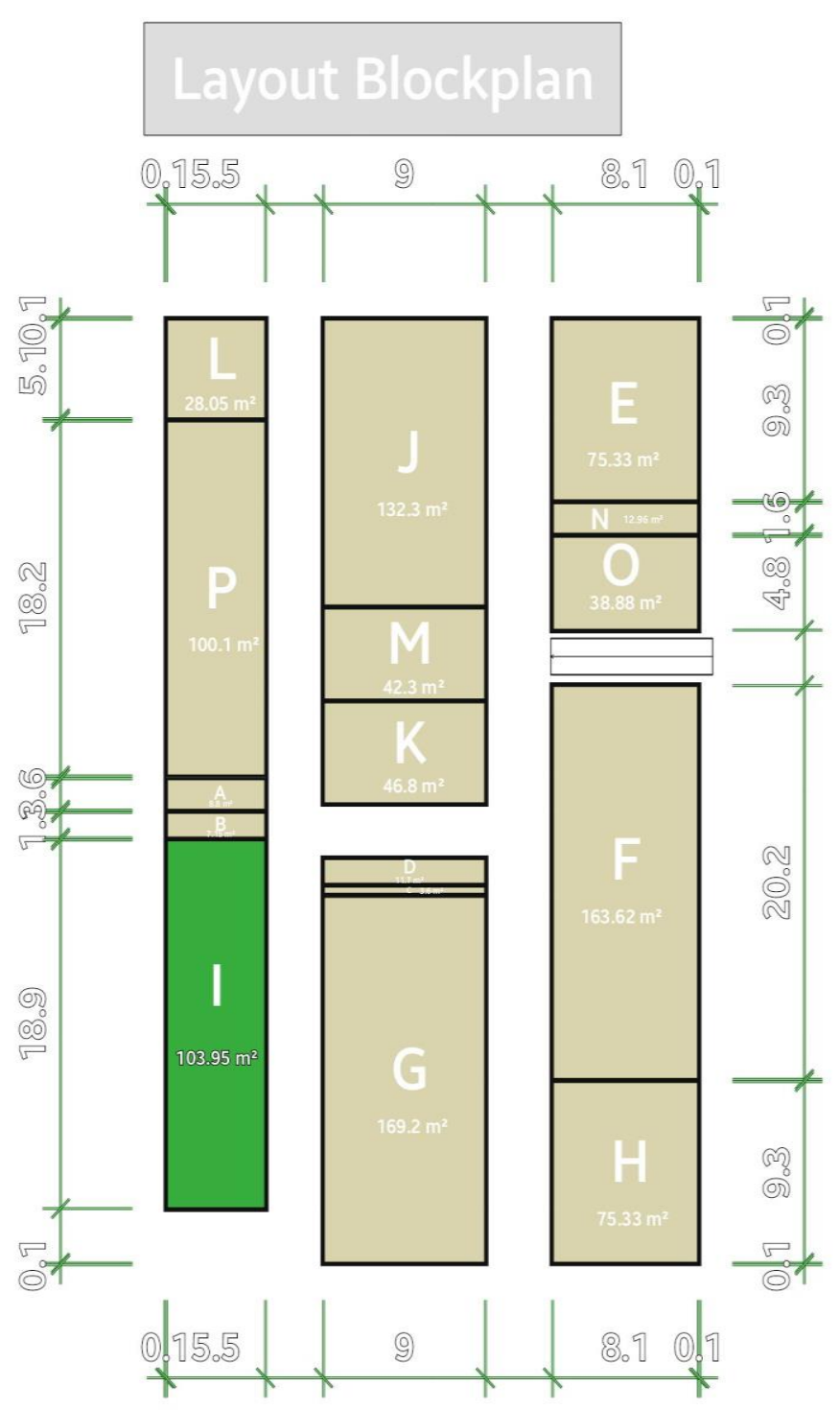

Gambar 6. Layout usulan perbaikan tata letak berdasarkan metode Blocplan.

Analisis Perbandingan Tata Letak Awal dan Tata Letak Usulan

Systematic Layout Planning (SLP) dan Blocplan memiliki perbedaan dalam faktor penentuan perubahan dan juga ketelitian dalam mempertimbangkan perbaikan (Tabel 5 dan Tabel 6). SLP mempunyai faktor yang lebih detail seperti alur produksi dan pertimbangan-pertimbangan kualitatif, sedangkan Blocplan bersifat otomatis dan hanya mempertimbangkan sedikit faktor tanpa melihat alur produksi yang ada. Penggunaan Blocplan akan lebih baik ketika digunakan dalam perencanaan awal tata letak bukan dalam perancangan ulang tata letak.

Tabel 5. Analisis perbandingan SLP

\begin{tabular}{lccc}
\hline \multicolumn{1}{c}{ Atribut } & $\begin{array}{c}\text { Layout } \\
\text { awal }\end{array}$ & $\begin{array}{c}\text { Layout usulan metode } \\
\text { SLP }\end{array}$ & $\begin{array}{c}\text { Efisiensi } \\
(\%)\end{array}$ \\
\hline Total Jarak Antara Departemen Produksi (m) & 416 & 276 & 33,65 \\
Jarak Tempuh Aliran Material (m) & 1266 & 908,5 & 28,23 \\
Ongkos Material Handling (Rp) & 203.654 & 75.458 & 62,94 \\
\hline
\end{tabular}

Keterangan:

Layout awal didapatkan dari Tabel 1

Layout usulan metode SLP didapatkan dari Tabel 2

Persentase efisiensi = layout awal $\div$ layout usulan 
Tabel 6. Analisis perbandingan layout awal dengan metode Blocplan

\begin{tabular}{lccc}
\hline \multicolumn{1}{c}{ Atribut } & $\begin{array}{c}\text { Layout } \\
\text { awal }\end{array}$ & $\begin{array}{c}\text { Layout usulan metode } \\
\text { Blocplan }\end{array}$ & $\begin{array}{c}\text { Efisiensi } \\
(\%)\end{array}$ \\
\hline Total Jarak Antara Departemen Produksi $(\mathrm{m})$ & 416 & 486 & -17 \\
\hline Jarak Tempuh Aliran Material $(\mathrm{m})$ & 1266 & 760,2 & 40 \\
\hline Ongkos Material Handling $(\mathrm{Rp})$ & 203.654 & 185.097 & 9 \\
\hline
\end{tabular}

Keterangan:

Layout awal didapatkan dari Tabel 1

Layout usulan metode SLP didapatkan dari Tabel 4

Persentase efisiensi = layout awal $\div$ layout usulan

Total jarak antar departemen yang dimiliki layout alternatif SLP lebih kecil dibanding layout alternatif Blocplan, namun jarak tempuh aliran material layout alternatif SLP lebih besar dibanding layout alternatif Blocplan. Hal tersebut dikarenakan pemakaian alat berat dalam pengangkutan bahan sehingga $\mathrm{OMH}$ dari layout alternatif Blocplan juga lebih besar dari layout alternatif SLP. Pemilihan layout alternatif lebih berdasar pada $\mathrm{OMH}$ agar dapat mengurangi biaya produksi sehingga dapat meningkatkan efisiensi produksi pada PT Sinar Mayang Lestari.

\section{SIMPULAN}

Perancangan ulang tata letak PT Sinar Mayang Lestari terpilih menggunakan metode Systematic Layout Planning (SLP) menunjukkan bahwa metode SLP dapat meminimalisasi jarak antar departemen produksi dari $416 \mathrm{~m}$ menjadi $276 \mathrm{~m}$ atau berkurang sekitar 33,65\%. Dilihat dari sisi ongkos material handling, usulan tata letak dengan metode SLP berhasil memangkas biaya perpindahan material dari Rp203.645 menjadi Rp75.458 atau berkurang sekitar $62,94 \%$. Walaupun merancang perbaikan tata letak menggunakan metode Blocplan lebih mudah dan cepat, namun untuk mempertimbangkan pola aliran proses dengan metode produksi yang beragam, metode Blocplan tidak memperhitungkannya dengan matang sehingga jarak antar departemen produksi menjadi terlampau jauh.

\section{UCAPAN TERIMA KASIH}

Ucapan terima kasih disampaikan kepada PT Sinar Mayang Lestari atas kesempatan dan pengalaman yang Penulis peroleh selama berkerjasama dengan PT Sinar Mayang Lestari serta kepada Alifa Putri Anarghya atas bantuannya dalam melaksanakan penelitian ini.

\section{DAFTAR PUSTAKA}

Choir, M, DS Arief, dan M Siska. 2017. Desain ulang tata letak fasilitas produksi menggunakan metode systematic layout planning pada pabrik kelapa sawit Sungai Pagar. JOM FTeknik. 4(1): 1-6.

Direktorat Jenderal Perkebunan. 2019. Statistik perkebunan Indonesia 2017-2019: Kopi. Kementerian Pertanian Republik Indonesia.

Hasan. 2009. Action research: Desain penelitian integratif untuk mengatasi permasalahan masyarakat. AKSES: Jurnal Ekonomi dan Bisnis. 4(8): 177-188.

Husen, TA, PP Suryadhini, dan MD Astuti. 2020. Perancangan tata letak fasilitas untuk meminimasi jarak material handling pada UKM XYZ menggunakan metode ALDEP. Prosiding Seminar Dan Konferensi Nasional IDEC 2020, November. A08.1-A08.12.

International Coffee Organization. (2018). 10 Negara dengan Konsumsi Kopi Terbesar Dunia 2016/2017. Tersedia online pada https:/databoks.katadata.co.id/datapublish/20 18/12/12/indonesia-masuk-daftar-negarakonsumsi-kopi-terbesar-dunia. Diakses Juli 2020.

Nursandi, FH Mustofa, Rispianda. 2014. Rancangan tata letak fasilitas dengan menggunakan metode Blocplan (studi kasus PT. Kramatraya Sejahtera). Reka Integra. 3(1): 90-100.

Pangestika, JW, N Handayani, dan M Kholil. 2016. Usulan re-layout tata letak fasilitas produksi dengan menggunakan metode SLP di Departemen Produksi Bagian OT cair pada PT IKP. Jisi: Jurnal Integrasi Sistem Industri. 3(1): 29-38.

Riyanta, AB, dan R Febriyanti. 2018. Pengaruh kombinasi ekstrak biji kopi dan rimpang jahe terhadap sifat fisik sediaan foot sanitizer spray. Parapemikir: Jurnal Ilmiah Farmasi. 
7(2): 247-251.

Siregar, RM, D Sukatendel, dan U Tarigan. 2013. Wignjosoebroto, S. 2009. Tata Letak Pabrik dan Perancangan ulang tataletak fasilitas produksi dengan menerapkan algoritma Blocplan dan algoritma Corelap pada PT. XYZ. e-Jurnal
Teknik Industri FT USU. 1(1): 35-44.

Pemindahan Bahan (IK Gunarta, Ed.). Edisi Ke-3. Guna Widya. Surabaya. 